\title{
A Prospective Observational Study of Near-miss Events and Maternal Deaths in Obstetrics
}

\author{
${ }^{1}$ Shaveta Yadav, ${ }^{2}$ Smiti Nanda
}

\section{ABSTRACT}

Purpose: To study the incidence and causes of near-miss cases and maternal deaths (MDs) and also search the level of delay.

Materials and methods: The prospective observational study was carried out in the Department of Obstetrics and Gynecology for a period of one and a half year (September 2012 to February 2014). For identifying near-miss events, disease-specific criteria were used. Near-miss cases were identified among women with pregnancy-related complications whose diagnoses were meeting the criteria. Detailed information of maternal mortalities and near-miss cases for demographic features, underlying causes, treatment received, and level of delay were also obtained.

Results: There were 15,170 obstetric admission, 13,851 live births, 184 near-miss cases, and 60 MDs during the study period. The maternal near-miss (MNM) rate was 13.2/1,000 live births and maternal mortality ratio was $433.1 / 100,000$ live births. The mortality index (MD/MNM+MD) was reported as $25 \%$. The maternal mortality to near-miss ratio was $1: 3.07$. Severe maternal outcome rate (MNM/MNM+MD) was 17.6/1,000 live births. Hemorrhage $(54.89 \%)$ was the leading cause of nearmiss events followed by hypertension $(24.45 \%)$ and anemia (13.59\%). Hypertension (26.66\%) was responsible for most of the MDs followed by anemia (25\%), hemorrhage $(20 \%)$, and puerperal sepsis $(10 \%)$. The most common level of delay was found on the part of women and/or family to seek help.

Conclusion: Hypertension, hemorrhage, and anemia are leading causes of maternal morbidity and mortality. Lessons need to be learnt from cases of near-miss, which can serve as a useful tool in making strategies and putting efforts to reduce maternal mortality.

Keywords: Anemia, Hemorrhage, Hypertension, Maternal deaths, Maternal near-miss, Puerperal sepsis.

How to cite this article: Yadav S, Nanda S. A Prospective Observational Study of Near-miss Events and Maternal Deaths in Obstetrics. J South Asian Feder Obst Gynae 2016;8(4):261-265.

Source of support: Nil

Conflict of interest: None.

Date of received: 10 August 2016

Date of acceptance: 07 September 2016

Date of publication: October 2016

\footnotetext{
${ }^{1}$ Senior Resident, ${ }^{2}$ Senior Professor and Head

${ }^{1}$ Department of Obstetrics and Gynecology, BPS Government Medical College for Women, Sonepat, Haryana, India

${ }^{2}$ Department of Obstetrics and Gynecology, Pt. Bhagwat Dayal Sharma Post Graduate Institute of Medical Sciences, Rohtak Haryana, India

Corresponding Author: Shaveta Yadav, Senior Resident Department of Obstetrics and Gynecology, BPS Government Medical College for Women, Sonepat, Haryana, India, Phone: +911274260461, e-mail: sy.shweta7@gmail.com
}

\section{INTRODUCTION}

Maternal mortality remains a major public health challenge despite numerous strategies devised by the international community to curb it. Despite therapeutic advances and growing perception of the safety of child birth, morbidity and mortality continues to occur in obstetric patients. For every maternal death (MD) there are many serious life-threatening complications of pregnancy. Maternal mortality is frequently described as "just the tip of iceberg," implying that there is a vast base to the iceberg - maternal morbidity (near-miss), which remain largely undescribed and unnoticed. Yet, very little attention has been given to identify the cause of morbidity. Pregnant women's health status is not reflected by mortality indicators alone. Hence, the concept of nearmiss has been brought forward for present health care providing system. This concept is superior over maternal deaths in drawing attention to surviving women's reproductive health and lives and is equally applicable in developing countries as well as developed countries.

World Health Organization (WHO) defines maternal death as: "death of a women while pregnant or within 42 days of termination, irrespective of duration and site of pregnancy from any related to or aggravated by pregnancy or its management but not from accidental or incidental causes." ${ }^{1}$

Every day approximately 800 women die from preventable cause during pregnancy, child birth, and puerperium. A majority of all maternal deaths $(99 \%)$ occur in developing countries. ${ }^{2}$ The two regions, sub-Saharan Africa and Southern Asia, account for $85 \%$ of the global burden of maternal mortality. At the country level, two countries account for the one-third of global maternal deaths: India $(17 \%)$ followed by Nigeria $(14 \%){ }^{3}$

Since 1990, India has made a great progress in reducing the maternal death ratio from 560 in 1990 to 190 in 2013. Sri Lanka has reported decline from 49 to 29 during the same period. ${ }^{4}$ Maternal mortality in a nation with poor resources has been attributed to the " 3 delays"

1. Delay in deciding to seek care

2. Delay in reaching care in time

3. Delay in receiving adequate treatment

The WHO defines a maternal near-miss (MNM) case as "a woman who nearly died but survived a complication 
that occurred during pregnancy, childbirth or within 42 days of termination of pregnancy."

Near-miss cases occur more often than the maternal death and may generate more information because the women herself can be a source of data. Review of cases of near-miss has the potential to highlight both deficiencies and positive elements in the provision of obstetric services and to provide information about the epidemiology of severe obstetric complications. ${ }^{6}$

The present study was aimed to describe epidemiological profile, causes, and factors responsible for nearmiss cases and maternal outcome in regional tertiary health care center.

\section{MATERIALS AND METHODS}

The prospective observational study was carried out in the Department of Obstetrics and Gynecology for a period of one and a half year (September 2012-February 2014). All cases of near-miss and maternal deaths were taken. Near-miss cases were identified as per the criteria defined by WHO. ${ }^{7}$ Data were collected for their sociodemographic features, causes, mode of management, and ultimate outcome. All maternal deaths were analyzed and compared with these cases. The assessment of indicators of maternal morbidity and mortality was done on the basis of formulas recommended by WHO. ${ }^{8}$ Definitions of each criterion are as follows:

- Near-miss rate: Number of near-miss cases per 1,000 live births

- Maternal mortality ratio: Number of maternal deaths per 100,000 live births

- Maternal mortality/near-miss ratio: Ratio between near-miss and maternal deaths

- Severe maternal outcome ratio (SMOR): Number of women in life-threatening situation per (MD+MNM) 1,000 live births

- Mortality index: MD/MD+MNM (percentage).

\section{RESULTS}

During this study period, there were 15,170 obstetric admissions and 13,851 live births. There were 184 nearmiss patients and 60 maternal deaths. The MNM rate was 13.2/1,000 live births and maternal mortality ratio was $433.1 / 100,000$ live births. The mortality index was reported as $25 \%$. The maternal mortality to near-miss ratio was 1:3.07, which means for every 3 to 4 life-threatening conditions there was one maternal death. Different studies across the world have great variations. This ratio ranges from 1:19 (France), 1:11 (London) to 1:15 (USA). ${ }^{9-11}$ This variation in the ratio is because of high maternal mortality in developing countries like ours. Women reach health care facilities in a condition that it becomes really difficult to save them and unfortunately they land into mortality. The other indices are shown in Table 1.

Majority of women were in both the groups, were in the age group of 20 to 30 years, and were from rural background and lower socioeconomic status. The sociodemographic features of patients in both the groups are shown in Table 2.

There were $68.47 \%(126 / 184)$ patients in near-miss group and $78.33 \%(47 / 60)$ in maternal death group who were referred from outside. Missed opportunities by patient herself or at the peripheral centers from where the cases were referred to or the presence of substandard care at the periphery are shown in Table 3.

The main cause of near-miss was hemorrhage accounting for $54.89 \%$ of the causes. Hypertensive

Table 1: Study profile

\begin{tabular}{ll}
\hline Period & Sep 2012-Feb 2014 \\
\hline Total number of obstetric admissions & 15,170 \\
Total live births & 13,851 \\
Total near-miss cases & 184 \\
Total maternal deaths & 60 \\
Near-miss rate (MNM/LB) & $13.2 / 1,000$ live births \\
Maternal mortality ratio (MD/LB) & $433.1 / 100,000$ live births \\
Near-miss: Maternal death ratio & $3.07: 1$ \\
Mortality index (MD/MNM+MD) & 0.25 \\
Severe maternal outcome rate & $17.6 / 1,000$ live births \\
(MNM+MD)/LB & \\
\hline
\end{tabular}

Table 2: Demographic profile

\begin{tabular}{lll}
\hline Characteristics & $M N M(n=184)$ & $M D(n=60)$ \\
\hline $\begin{array}{l}\text { Age (years) (mean) } \\
\text { Obstetric formula }\end{array}$ & $25.38 \pm 4.04$ & $24.31 \pm 3.80$ \\
G1-G2 & $59(49.16 \%)$ & $28(71.75 \%)$ \\
$\geq$ G3 & $61(50.83 \%)$ & $11(28.20 \%)$ \\
P1-P2 & $41(64.06 \%)$ & $17(80.94 \%)$ \\
$\geq$ P3 & $23(35.93 \%)$ & $4(19.04 \%)$ \\
Socioeconomic status & & \\
Lower class & $149(80.97 \%)$ & $53(88.33 \%)$ \\
Middle class & $35(19.02 \%)$ & $7(11.66 \%)$ \\
Residential status & & \\
Rural & $106(57.60 \%)$ & $51(85 \%)$ \\
Urban & $78(42.40 \%)$ & $9(15 \%)$ \\
\hline
\end{tabular}

Table 3: Comparison of level of delay in maternal near-miss and maternal death groups

\begin{tabular}{lll}
\hline & $M N M(n=184)$ & $M D(n=60)$ \\
\hline $\begin{array}{l}\text { Delay on the part of women } \\
\text { (first delay) }\end{array}$ & $132(71.7 \%)$ & $54(90 \%)$ \\
$\begin{array}{l}\text { Delay due to transport problem } \\
\text { (second delay) }\end{array}$ & $68(36.95 \%)$ & $15(25 \%)$ \\
$\begin{array}{l}\text { Delay on the part of health care } \\
\text { center (third delay) }\end{array}$ & & \\
$\begin{array}{l}\text { Nonavailability of infrastructure } \\
\text { Nonavailability of blood }\end{array}$ & $82(44.56 \%)$ & $35(58.33 \%)$ \\
\hline
\end{tabular}


A Prospective Observational Study of Near-miss Events and Maternal Deaths in Obstetrics

Table 4: Primary outcomes in both groups

\begin{tabular}{|c|c|c|c|c|}
\hline Cause & Total & MNM & $M D$ & Mortality index (\%) \\
\hline Hemorrhage & 113 & $101(89.38 \%)$ & $12(10.61 \%)$ & 10.61 \\
\hline Early pregnancy & & 24 & - & \\
\hline Late pregnancy & & 77 & 12 & 13.48 \\
\hline $\mathrm{APH}$ & & 14 & 4 & 44.44 \\
\hline $\mathrm{PPH}$ & & 37 & 7 & 15.90 \\
\hline Rupture uterus & & 14 & 1 & 6.66 \\
\hline Uterine inversion & & 6 & - & \\
\hline Morbidly adherent placenta & & 6 & - & \\
\hline Hypertension & 61 & $45(73.77 \%)$ & $16(35.55 \%)$ & 26.22 \\
\hline Eclampsia & & 30 & 10 & 25 \\
\hline Preeclampsia & & 15 & 6 & 28.5 \\
\hline Severe anemia & 40 & $25(62.5 \%)$ & $15(37.5 \%)$ & 37.5 \\
\hline Others & 15 & $4(26.66 \%)$ & $11(73.33 \%)$ & 73.33 \\
\hline
\end{tabular}

Table 5: Blood transfusion in both groups

\begin{tabular}{lll}
\hline & $\begin{array}{l}\text { Maternal near- } \\
\text { miss }(n=184)\end{array}$ & $\begin{array}{l}\text { Maternal death } \\
(n=60)\end{array}$ \\
\cline { 2 - 3 } & $n(\%)$ & $n(\%)$ \\
\hline Received blood transfusion & $162(88.04 \%)$ & $38(63.33 \%)$ \\
Not received blood transfusion & $22(11.95 \%)$ & $22(36.66 \%)$ \\
\hline
\end{tabular}

disorders were second-most common cause of nearmiss accounting for $24.45 \%$. The main obstetric factors responsible for maternal deaths were hypertension $(26.66 \%)$, followed by (f/b) severe anemia (25\%), hemorrhage $(20 \%)$, and puerperal sepsis $(10 \%)$. The causes and mortality index for each cause is shown in Table 4 .

Timely ICU care can prevent maternal deaths, because obstetric patients are young and they recover well with appropriate ICU care. There were $32.06 \%$ patients who required ICU admission in addition to other interventions in near-miss group. In our study, 162 patients in near-miss group and 38 patients in maternal death were transfused blood and blood components (Table 5). There were 1,377 units of group blood and blood components transfused to patients in near-miss group and 258 units of blood and blood components to maternal death group.

\section{DISCUSSION}

Death of mother is a tragic event. In practical life it has a severe impact on the life of family, community, and eventually the nation. The young surviving motherless children are unable to cope with the daily living and therefore are at increased risk of death. The study shows that severe acute maternal morbidities occur in considerable percentage of women managed in this obstetric unit. Here, obstetricians confront life-saving emergency situation in almost 1 out of 4 women. The disparity in near-miss cases in different studies is because of the difference in the criteria used to identify near-miss cases. But near-miss to maternal mortality ratio (1:3.07) is lower than other studies because of high mortality rate. Our center is one of the most crowded hospitals in India with more than 10,000 deliveries per year. Patients are referred from all over the state and nearby states, some in real bad condition which are difficult to save even with best of our care, resulting in high mortality.

In our study, majority of the patients were from lower class (72.28\% in MNM group and 57.60\% in MD group) and hailing from rural background $(57.60 \%$ in MNM group and $88.33 \%$ in MD group). They remain greatly dissociated from health care system. They are unfamiliar to various health programs that provide maternal health care free of cost and thus remain deprived of those facilities. Most of the women in both the groups never received antenatal care $(57.06 \%$ patients in MNM group and $68.33 \%$ in MD group). This is a major lacuna that needs to be corrected. With proper antenatal care highrisk pregnancy can be identified, treated, or referred, before they turn into near-miss condition or become maternal mortality.

To understand the gaps in access to adequate management of obstetric emergencies leading to severe maternal complications and death, three delays have been identified.

The first delay is in deciding to seek care by the women and/or her family as they are unaware of need for care, the danger signs are not recognized, or there is lack of support of the family. Sometimes, there are taboos associated in the family, negligence on the part of family members regarding health of female, illiteracy, and poverty, which precludes them seeking heath care. In our study first delay was present in $71 \%$ cases in MNM group and $90 \%$ in maternal death group. It corresponds with the study conducted by Yunus et $\mathrm{al}^{12}$ in which the first delay was observed as the major cause of delay in $80 \%$ of the patients in both the groups. 
The second delay is in reaching an adequate health care facility as the service may not exist or may be inaccessible for reasons, such as distance, lack of transport, cost, or socioeconomic barriers. Sometimes, this delay may cost the life of the patient. Woman's condition deteriorates as they are referred from hospitals which refuse to admit them due to incapability of dealing with such cases. In Haryana, good ambulance services are available. Thus, this level of delay was seen only in $36.95 \%$ patients in MNM group and 25\% in MD group.

The third delay occurs in receiving care at the facility resulting from errors in diagnosis and clinical decision making, or lack of medical supplies and of staff proficiency in the management of obstetric emergencies at the peripheral health care center. In our study, majority of patients in both groups were referred because of lack of blood and lack of infrastructure like operation theater, ICU, etc. There were $44.56 \%$ patients in MNM group and $58.33 \%$ in MD group who were referred due to lack of infrastructure. There were $44 \%$ in MNM group and $55 \%$ in MD group, referred because of nonavailability of blood. It is very important to maintain a good standard of care at the primary and community health care center if utilization of proper obstetric services among population is to be encouraged.

In many cases, there were overlapping of the delays. Worldwide hemorrhage is the leading cause of death accounting for $27.1 \%$ of all maternal deaths. Hypertension accounted for $14.0 \%$ of maternal deaths and sepsis for $10.7 \% .^{13}$

The main cause of near-miss was hemorrhage, accounting for $54.89 \%$ of the causes. There were $20.10 \%$ cases due to postpartum hemorrhage (PPH), 7.60\% each for antepartum hemorrhage (APH) and rupture uterus, $3.26 \%$ each for morbidly adherent placenta and uterine inversion. Hypertensive disorders were the second-most common cause of near-miss accounting for $24.45 \%$.

This was similar to the study by Olufemi et al in which most common cause of near-miss was hemorrhage $(49.6 \%), \mathrm{f} / \mathrm{b}$ hypertension $(31.4 \%)$ and anemia $(10.7 \%){ }^{14}$ In a similar study by Ashmarana et al, the causes of nearmiss were hemorrhage $45.5 \%$, hypertensive disorders $16 \%$, and infection $7.6 \%{ }^{14}$

The main obstetric factors responsible for maternal deaths were hypertension $(26.66 \%), \mathrm{f} / \mathrm{b}$ severe anemia $(25 \%)$, hemorrhage $(20 \%)$, and puerperal sepsis $(10 \%)$. In a study by Olufemi et al, the causes of maternal deaths were hypertension (31.4\%), hemorrhage (30.2\%), puerperal sepsis (19.5\%), and anemia (12.2\%). ${ }^{14}$ In both the studies, hypertension was the most common cause of maternal death, and hemorrhage was also one of the important cause.
Severe bleeding after birth can kill a healthy woman within hours if she is unattended. It occurs in about $10.5 \%$ of births and accounts for 1,30,000 maternal deaths annually. ${ }^{15}$ Active management of the third stage of labor (AMTSL) is a feasible and inexpensive intervention that can help save thousands of women's lives. The AMTSL involves three basic procedures: The use of uterotonic agents (preferably oxytocin) within 1 minute following the delivery of the baby, delivery of the placenta with controlled cord traction, and massage of the uterus after delivery of the placenta. It needs to be taught to birth attendants and auxiliary nurse midwives at the peripheral center.

Timely blood transfusion can save the life. Many women die due to lack of blood supply at the peripheral centers. They are referred from these centers in a critical situation. Their condition deteriorates further till they reach tertiary center and it becomes difficult to save their life. Thus, blood and blood components should be made available in the periphery center to decrease maternal mortality and morbidity.

Infection after childbirth can be eliminated if good hygiene is practiced and if early signs of infection are recognized and treated in a timely manner.

Preeclampsia should be detected and appropriately managed before the onset of convulsions (eclampsia) and other life-threatening complications. Administering drugs, such as magnesium sulfate for preeclampsia can lower a woman's risk of developing eclampsia.

Anemia is the underlying cause of almost all the morbidities and mortalities. All women should be educated about the importance of good diet and iron supplements intake during pregnancy.

Short interpregnancy interval and multiparity are responsible for high prevalence of anemia. Contraceptive practice is poor among these women. This may be due to improper knowledge about contraceptive methods, social inhibitions, and myths associated with contraceptive measures.

Along with increased awareness of one's own health, health education may go a long way in improving the quality of obstetric care.

The major causes of near-miss cases were similar to the causes of maternal mortality of India. Lessons can be learned from cases of near-miss, which can serve as a useful tool in reducing morbidity and mortality rate.

\section{CONCLUSION}

Community perspectives of motherhood, which are embedded in local customs and in specific behavioral norms, need to be taken into account when strengthening safe motherhood programs. Improving community 
level of management of complications and emergencies (understanding severity of problems, preparedness, and arrangements for referral) will have to go hand-in-hand with improvements in health services to make referrals meaningful and to further reduce maternal mortality and morbidity in poor rural areas.

Review of cases of near-miss has the potential to highlight both deficiencies and positive elements in the provision of obstetric services and to provide information about the epidemiology of severe obstetric complications.

The major causes of near-miss cases were similar to the causes of maternal mortality of India. Lessons can be learnt from cases of near-miss, which can be used to reduce maternal mortality. The addition of near-miss audits will allow the care of critically ill women to be analyzed, deficiencies at the level of health care system to be identified, and comparison within and between institutions and countries to be carried out over time. This will, ultimately, improve the quality of obstetric care and further reduce maternal morbidity and mortality worldwide.

\section{REFERENCES}

1. Park K. Preventive medicine in obstetric paediatrics and geriatrics. In: Park's Textbook of preventive and social medicine. 21st ed. Jabalpur: Bansaridas Bhanot; 2011. p. $481-560$.

2. Central Intelligence Agency. Country comparison: maternal mortality rate [online]. 2010. Available from: http:/ / www.cia. gov/library/publication/theworld.factbook.

3. World Health Organization. Trends in maternal mortality 1999-2010 [accessed 2013 Oct 10]. Available from: http: / / www. who.int/reproductivehealth/publications/monitoring/ 9789241503631/en/.

4. United Nations Statistics Division. Millennium development goal indicator [accessed 2014 Oct 12]. Available from: http: / / unstats.un.org/unsd/mdg/SeriesDetail.aspx?srid=553.
5. UNFPA. Maternal mortality update 2002 a focus on emergency obstetric care [accessed 2014 Oct 12]. Available from: http:/ / unfpa.org/public/home/publications/pid/2478.

6. Jayaratnam S, De Costa C, Howat P. Developing an assessment tool for maternal morbidity near-miss - a prospective study in a large regional hospital. Aust N Z J Obstet Gynaecol 2011 Oct; 51(5):421-425.

7. WHO. Evaluation the quality of care for severe pregnancy complications: the WHOnear-miss approach for maternal health [accessed 2014 Jul 3]. Available from: http:/ /www.who.int/ reproductivehealth/publications/monitoring/9789241502221/ en/.

8. Say L, Souza JP, Pattinson RC, WHO Working Group on Maternal Mortality and Morbidity Classifications. Maternal near-miss towards a standard tool for monitoring quality of maternal health. Best Pract Res Clin Obstet Gynaecol 2009 Jun;23(3):287-296.

9. Waterstone M, Bewley S, Wolfe C. Incidence and predictors of severe obstetric morbidity: case-control study. BMJ 2001 May 5;322(7294):1089-1093.

10. Bouvier-Colle MH, Salanave B, Ancel PY, Varnoux N, Fernandez H, Papiernik E, Bréart G, Benhamou D, Boutroy P, Caillier I, et al. Obstetric patients treated in intensive care units and maternal mortality. regional teams for the survey. Eur J Obstet Gynecol Reprod Biol 1996 Mar;65(1):121-125.

11. Souza JP, Cecatti JG, Faundes A, Morais SS, Villar J, Carroli G, Gulmezoglu M, Wojdyla D, Zavaleta N, Donner A, et al. Maternal near-miss and maternal death in the World Health Organization's 2005 global survey on maternal and perinatal health. Bull World Health Organ 2010 Feb;88(2):113-119.

12. Yunus S, Kauser S, Ali S. Three 'Delays' as a framework for critical analysis of maternal near-miss and maternal mortality. J South Asian Feder Obstet Gynaecol 2013 May-Aug;5(2):57-59.

13. WHO. Maternal mortality [accessed 2014 Aug 29]. Available from: http:/ /www.int/mediacentre/factsheets/fs348/en/..

14. Oladapo OT, Sule-Odu AO, Olatunji AO, Daniel OJ. "Nearmiss" obstetric events and maternal death in Sagamu, Nigeria: a retrospective study. Reprod health 2005 Nov 1;2:9-15.

15. Kushwah B, Singh AP, Natung P. Analysis of various criteria for identification of severe acute maternal morbidity in a rural tertiary health care centre: a prospective one year study. Int J Med Sci Public Health 2014;3(3):330-334. 